\title{
Business Group Performance in China: Ownership and Temporal Considerations 中国企业集团的绩效：所有制形式与时间因素
}

\author{
Michael Carney, Daniel Shapiro, and Yao Tang (唐遥)
}

摘要

本文提出了体制空隙假设, 即在一个制度效率较低、并存在大量市场失败案例的环境 中，具有集团附属资格的企业会有较高的经营绩效。这种由集团附属资格带来的正效 应会随着市场制度质量的提高而下降。我们进一步假设企业所有制的差别会影响集团 附属资格的价值及其持续性。以1999年上市的476家企业和2004年的467家配对公司为 研究样本，我们发现这一与 “时间” 有关的假设得到了支持：集团的附属资格能够提 高公司的绩效，但是附属资格的价值随时间而下降。同时，研究结果还支持了国有资 本的 “帮手” 假设, 即具有高比例国有资本的公司最初可从其附属资格获得一个放大 的价值效应，但这种效应在2004年后消失了。结果表明，中国的政策制定者开始建立 一个基于制度和市场的机制，从而有利于独立、没有附属资格的公司加入市场竞争。

关键词：企业集团、中国、制度空隙、所有权、绩效

\section{International Strategic Human Resource}

Management: A Comparative Case Analysis of Spanish Firms in China

\section{国际战略性人力资源管理：关于西班牙在中国的 企业的比较性案例分析}

\section{Yingying Zhang (张荣荣), Simon Dolan, Tony Lingham, and Yochanan Altman}

摘要

本文研究了中国新兴市场上人力资源在战略形成过程中的角色问题。采用质性的原始 资料驱动的主题分析方法，我们比较了从中国境内的6家西班牙公司收集到的相关数 据。研究结果发现拥有良好绩效的公司使用的是动态适应逻辑，而绩效较差的公司则 使用静态结构逻辑。最后, 我们提出了一个战略性人力资源管理的动态适应模型, 着 重强调战略、人力资源和国际管理三个领域之间的动态和非正式过程。

关键词：中国、人力资源、国际商业、西班牙、战略 


\title{
Social Exchange and Knowledge Sharing among Knowledge Workers: The Moderating Role of Perceived Job Security
}

\section{知识工作者间的社会交换和知识共享：工作安全感的调节 作用}

\author{
Kathryn M. Bartol, Wei Liu (刘玮), \\ Xiangquan Zeng (曾湘泉), and Kelu Wu (吴克禄)
}

摘要

\begin{abstract}
基于组织支持理论(POS)和员工-组织关系理论, 本文研究了POS和知识共享间的关系, 同时考虑了工作安全感的调节效应。研究参与者包括来自中国信息技术行业的 255 名专 家, 以及她/他们的上司。结果发现, POS和知识共享存在正相关关系, 并且如我们所 预测的，工作安全感则调节了这一关系。具体而言，POS和员工知识共享间的正关系 仅仅存在于那些在组织中有较高工作安全感的员工中。相反, 这一关系在那些工作安 全感较低的员工中并不显著。这一结果与员工-组织关系理论的观点是相一致的。这一 理论认为, 雇主对员工的有限投资有可能减弱员工对组织的贡献。研究结果也与社会 交换理论的观点一致，互惠关系是建立在开放式交换的基础上，这种关系的发展与短 期雇佣是不同的。
\end{abstract}

关键词：中国、雇佣关系、知识共享、工作安全感、组织支持(POS)、社会交换

\section{How Much Does National Culture Constrain Organizational Gulture?}

\section{国家文化在多大程度上会约束组织文化？}

\section{Barry Gerhart}

摘要

战略管理理论（如资源论）认为，尽管存在环境约束，但是组织文化（以及相关的人 力资源管理实践) 的差异使得企业依然有巨大的空间实现差异化, 并以此获得持续竞 争优势。相反, 其它观点则认为管理实践和组织文化是国家文化的反映, 或受到它的 约束。这种约束在一定程度上是存在的, 国家内组织文化上的差异应该很小, 而国家 间组织文化的差异则应比较大。从统计学的角度, 第一个问题是：国家影响的效应值 有多大? 这一效应越大，国家文化的约束作用就越大。第二、这种国家效应在多大程 度上可以归因于国家文化差异? 本文发现组织文化的大部分变异并不能由国家来解 释; 在国家解释的变异中, 只有很小一部分可以归因于国家文化差异。因此, 相比公 认的观点, 组织差异化的空间还很大。第三、在什么样的环境下, 国家和其文化效应 表现的更强或者更弱? 本文提出了一个模型来说明，在个体文化价值观和相关变量差 异较大的国家里, 组织文化差异的空间更大。

关键词：跨文化研究、文化、人力资源管理、组织行为、战略管理 


\section{Organizational Knowledge Creation in the Chinese Context}

\section{中国背景下的组织知识创造}

\section{Ian J. Walsh, Mamta Bhatt, and Jean M. Bartunek}

摘要

通过研究不同所有制形式的中国企业为创造组织知识而做出的制度性改变, 本文阐述 了组织知识创造理论。以动态制度观点为基础, 我们总结了中国背景的突出特征, 并 提出了不同组织形式下组织知识创造的假说。我们进一步讨论了持续的制度化对中国 组织知识创造模式的影响, 以及其对创新的影响。最后, 我们就模型的理论含意进行 了讨论, 提出了进一步研究的建议。

关键词：中国、情景化研究、创新、知识创造、组织形式 